\title{
The Mexico Consensus: a resolution of the fifth General Assembly of the International Rehabilitation Council for Torture Victims, 9 December 2016
}

The General Assembly of the International Rehabilitation Council for Torture Victims (IRCT) adopted a resolution setting out the collective position of its global membership, which consists of 151 centres in 74 countries.

\section{Considering}

1.That the membership of the International Rehabilitation Council for Torture Victims, IRCT - comprising of 152 rehabilitation centres for torture victims, in 74 countries worldwide - held its Tenth Scientific Symposium and its Fifth General Assembly in the City of Mexico, United Mexican States, from 4 to 9 December 2016;

2. That during the IRCT 10th International Scientific Symposium, we shared our global knowledge on rehabilitation methods based on evidence derived from the experiences matched to the needs of torture survivors from our work in different contexts around the world. This significant advance in the IRCT's strategy of mapping the global knowledge on rehabilitation provides a strong basis for understanding how appropriate rehabilitation services can best reach as many victims as possible and be a powerful tool for advocacy;

3. That on this day preceding United Nations Human Rights Day, it must be noted that the right to personal, family, community and social integrity exists at the centre of our notions of fundamental rights; and torture and cruel, inhuman and degrading treatment are a plague to our humanity;
4. Our desire to see a world without torture, our experience and understanding of the impact of torture upon individuals, families, communities, and societies: and building upon our efforts to prevent torture, fight impunity and provide redress and holistic rehabilitation to victims;

The General Assembly of the International Rehabilitation Council for Torture Victims, in its Fifth ordinary session,

\section{Declares}

5. That it is deeply concerned that torture and other grave human rights violations, including extrajudicial killings and enforced disappearances, continue to be widespread and often systemic in countries worldwide: and that rhetoric instigating or condoning torture and stigmatising victims is growing in all regions of the world;

6 . That it is deeply concerned by the growing number of human rights violations and victims of torture due to increasing conflicts, the growth of authoritarianism, persecution and discrimination, among other reasons, which have caused an increase in populations on the move; 


\section{Demands}

7. That States cease all practices of torture and cruel, inhuman and degrading treatment and fully implement their legal and moral obligations to prevent, prosecute and provide redress that includes reconciliation, for torture, including through the effective investigation and documentation of torture and the provision of holistic rehabilitation to individuals, families, communities and societies;

8. That States protect human rights defenders, rehabilitation providers and others working to support torture victims from all forms of discrimination, harassment, persecution and other forms of suppression for the exercise of their professional duties and activities;

9. That States address the underlying causes of torture and cruel, inhuman and degrading treatment, as well as all other grave violations of human rights;

\section{Resolves}

10. That holistic rehabilitation to support victims in concert with other actions to prevent torture, fight impunity and provide redress is an integral component of eradicating torture. We express our concerns about the severe underfunding of rehabilitation services globally, in a context where IRCT members experience an ever-increasing demand for rehabilitation services;

11. As we collectively seek to respond to the current situation of torture and other grave human rights violations, the IRCT membership emphasises that the rehabilitation response must be based on the global knowledge and understanding in our field, as well as human rights principles and a shared understanding of what constitutes effective rehabilitation services;

\section{Further resolves}

12. That States must provide all victims of torture and other cruel, inhuman and degrading treatment with access to a choice of rehabilitation services that are inclusive and multidisciplinary in nature and that meet their specific and diverse needs, taking into consideration that torture impacts every aspect of the individual's physical, psychological, material, familial, social, spiritual and legal life;

13. Holistic rehabilitation services must be rendered in full respect of the victim's agency and with their full and meaningful participation in their own rehabilitation process and the consideration of their views in the decisions made by service providers;

14. The wellbeing of torture victims, as well as professional ethical standards and principles, including on informed consent, confidentiality, 'do no harm', and the best interests of victims, must be at the centre of independent and accountable rehabilitation services according to the principles of General Comment 3;

\section{Decides}

15. To work together in solidarity and mutual support to further the common mission, combat ongoing oppression and human rights violations in accordance with international human rights standards, and implement the principles and recommendations set forth in this resolution to ensure that torture victims can access independent and accountable holistic rehabilitation services tailored to their specific and diverse needs;

16. To work together to promote a substantial increase in the global resources available to the provision of rehabilitation services to torture victims and, in this 
regard, instructs the IRCT Secretariat to facilitate a working group to further advance this agenda;

17. To document systematically the practice of torture as reported by torture victims and conduct assessments, in accordance with the Istanbul Protocol, to demonstrate the impact of torture on individuals, families, communities and society, and the need for rehabilitation. Use this knowledge to counter any attempt to condone or instigate torture and promote policies that contribute to its eradication;

18. To inform relevant government authorities and other stakeholders about the consequences of torture on the individual, family, community and society. In doing so, ensure that victims' rights to confidentiality and privacy is protected;

19. To advocate for the reform or implementation of laws and policies regarding holistic rehabilitation in contexts where the State is not meeting its international obligations to provide the means to achieve as full rehabilitation as possible. Where relevant, encourage States to ratify and implement the UN Convention against Torture and its Optional Protocol;

20. To advocate for State parties to the UN Convention against Torture to provide funding (either directly or indirectly) to national torture rehabilitation services and the United Nations Voluntary Fund for Victims of Torture, in ways that guarantee their independence, autonomy and sustainability and do not compromise their ability to provide rehabilitation on a non-discriminatory basis. Where no such rehabilitation services are available, IRCT members will advocate for the establishment and funding of rehabilitation services;

21 . To conduct rigorous and ethical research, with diverse outlooks and perspectives, to benefit the torture victims we serve. This includes documenting torture and its health consequences, identifying and addressing the needs of torture victims, and identifying, developing and evaluating effective treatment modalities that are both individual and holistic in nature;

22. To share good practice solutions in research and documentation, engage in capacity-building exchanges to support the growth and sustainability of skilled professionals, and share specialised knowledge in the field of torture rehabilitation to enhance the global fight to eradicate torture; and

23. To work jointly to enhance accountability towards victims, including in relation to relevant international, regional, national and local stakeholders. 